\title{
Thermal degradation of organic additives used in colloidal shaping of ceramics investigated by the coupled DTA/TG/MS analysis
}

\author{
Paulina Wiecinska ${ }^{1}$
}

Received: 4 March 2015 / Accepted: 22 September 2015/Published online: 3 October 2015

(C) The Author(s) 2015. This article is published with open access at Springerlink.com

\begin{abstract}
The paper presents the analysis of thermal decomposition of selected organic additives, which are commonly used in shaping of ceramic materials by colloidal methods. Shaping of ceramics requires using different additives which then are burned out during sintering process. For this reason, the knowledge about thermal degradation of organics used, as well as decomposition products, seems to be very important from the application point of view. The analyzed substances were as follows: diammonium hydrocitrate, citric acid, ammonium salt of acrylic polymer, L-ascorbic acid, $N, N, N^{\prime}, N^{\prime}$-tetramethylethylenediamine, and ammonium persulfate. The thermal analysis has been done on the apparatus coupled with mass spectrometer what allowed to observe what types of gasses are released to the atmosphere during heating. The obtained results showed important differences in thermal degradation of organic additives. It was possible to determine at what temperature regions harmful gases like $\mathrm{N}_{2} \mathrm{O}, \mathrm{NO}_{2}$, or $\mathrm{SO}_{2}$ are released from the organics and which additives can be treated as environmentally friendly.
\end{abstract}

Keywords Thermal degradation - Organics - Colloidal shaping $\cdot$ Mass spectrometer

\section{Introduction}

Fabrication of advanced ceramic materials requires the use of various organic additives which facilitate shaping process of non-plastic ceramic powders. The appropriate

Paulina Wiecinska

pwiecinska@ch.pw.edu.pl

1 Faculty of Chemistry, Warsaw University of Technology, 3 Noakowskiego St., 00-664 Warsaw, Poland selection of additives is especially important in case of colloidal processing [1], in methods like: slip casting [2], gelcasting [3, 4], tape casting [5], and mechanical foaming [6]. The number of different organics needed in a shaping process ranges from two to eight. The organic substances can play the role of dispersing agents which stabilize suspensions [7-9], binders which hold particles together [10], plasticizers which give elasticity [11], foaming agents which allow to obtain porous materials [12], monomers [13] together with activators [14] and initiators of polymerization [15] which allow to create polymeric network around non-plastic particles, etc. Organic additives are subsequently burned out during sintering process. They are indispensible in shaping step but must be then eliminated in order to obtain pure ceramic phase [16]. Organic substances thermally decompose during heating, and as a result different gases are released into the atmosphere. Information about temperature range of organics degradation is very useful in elaboration of sintering conditions, such as heating rate or dwell time. Two violent releases of gases from ceramic samples can lead to their deformation or cracking. The very useful tools which allow to determine the thermal degradation characteristics of substances during decomposition are DTA/TG and DSC analyses [17-20]. Additionally, coupling of the DTA apparatus with mass spectrometer makes it possible to analyze type of gases released to the atmosphere [21].

The author has chosen six organic additives, commonly used in colloidal shaping of ceramics in order to examine their behavior during thermal heating. The analyzed substances were as follows: diammonium hydrocitrate, citric acid, Dispex A-40 (ammonium salt of an acrylic polymer in water), $N, N, N^{\prime}, N^{\prime}$-tetramethylethylenediamine, L-ascorbic acid, and ammonium persulfate. In the previous paper, thermal decomposition of selected organic monomers used 
in gelcasting process was reported [22]. This paper develops the topic of thermal degradation of substances commonly used in colloidal shaping of ceramics.

\section{Materials and experimental procedure}

Six organic substances have been chosen for the analysis. The first three chemicals are commonly used as dispersing agents which allow to obtain time-stable and low-viscosity ceramic suspensions. The dispersants used were as follows: diammonium hydrocitrate, citric acid, and Dispex A-40 (an ammonium salt of an acrylic polymer in water.). The next chemicals used- $N, N, N^{\prime}, N^{\prime}$-tetramethylethylenediamine (TEMED) and L-ascorbic acid-are the activators of radical polymerization, commonly used in shaping of ceramics by gelcasting method. The last analyzed compound was ammonium persulfate which is a water-soluble initiator of radical polymerization, also used in gelcasting. The chemical formulae of analyzed substances is shown in Table 1.

DTA/TG measurements were carried out by using Netzsch STA 449C coupled with quadrupole mass spectrometer Netzsch QMS 403C. The heating rate was $5{ }^{\circ} \mathrm{C} \mathrm{min}^{-1}$, and the final temperature was $1000^{\circ} \mathrm{C}$. The measurements were performed in the constant flow of two gases: argon$10 \mathrm{~mL} \min ^{-1}$ (protective gas) and synthetic air (75:25 $\left.\mathrm{N}_{2}: \mathrm{O}_{2}\right)-60 \mathrm{~mL} \mathrm{~min}^{-1}$. The sample placed in the crucible contained $300 \mathrm{mg}$ of high-purity alpha alumina (TM-DAR from Tamei Chemicals, Japan) and $15 \mathrm{mg}$ of analyzed organic additive. Alumina which was non-reactive during heating prevented sticking of melted organics to crucible walls. Mass spectrometer was set to detect certain $\mathrm{m} / \mathrm{z}$ values and is listed in Table 2. Value $100 \%$ corresponds to the main $\mathrm{m} / \mathrm{z}$ value characteristic for a certain compound in the mass spectrum. In order to confirm the presence of given substance, the second $\mathrm{m} / \mathrm{z}$ value had to be detected by the spectrometer. The intensity of the second peak in the mass spectrum is related to the main $\mathrm{m} / \mathrm{z}$ value of the compound. It is worth to mention that $m / z$ values $14,16,32$, although useful in determination of the presence of ammonia or $\mathrm{NO}_{x}$, have not been taken into consideration because they refer also to $\mathrm{N}_{2}$ and $\mathrm{O}_{2}$, which constantly flow through the apparatus. The analysis was performed in the oxidizing atmosphere; therefore, the analyzed gases were the products of complete oxidation. Ammonia was supposed to appear during heating of TEMED and ammonium persulfate.

\section{Results and discussion}

Figure 1 presents DTA/TG/DTG curves of diammonium hydrocitrate (DAC) thermal degradation. The total mass loss was $100 \%$ what indicates that the whole DAC has decomposed, as expected. Mass loss is observed until ca. $659^{\circ} \mathrm{C}$. DAC decomposition goes in few stages according

Table 1 Organic additives used in the research

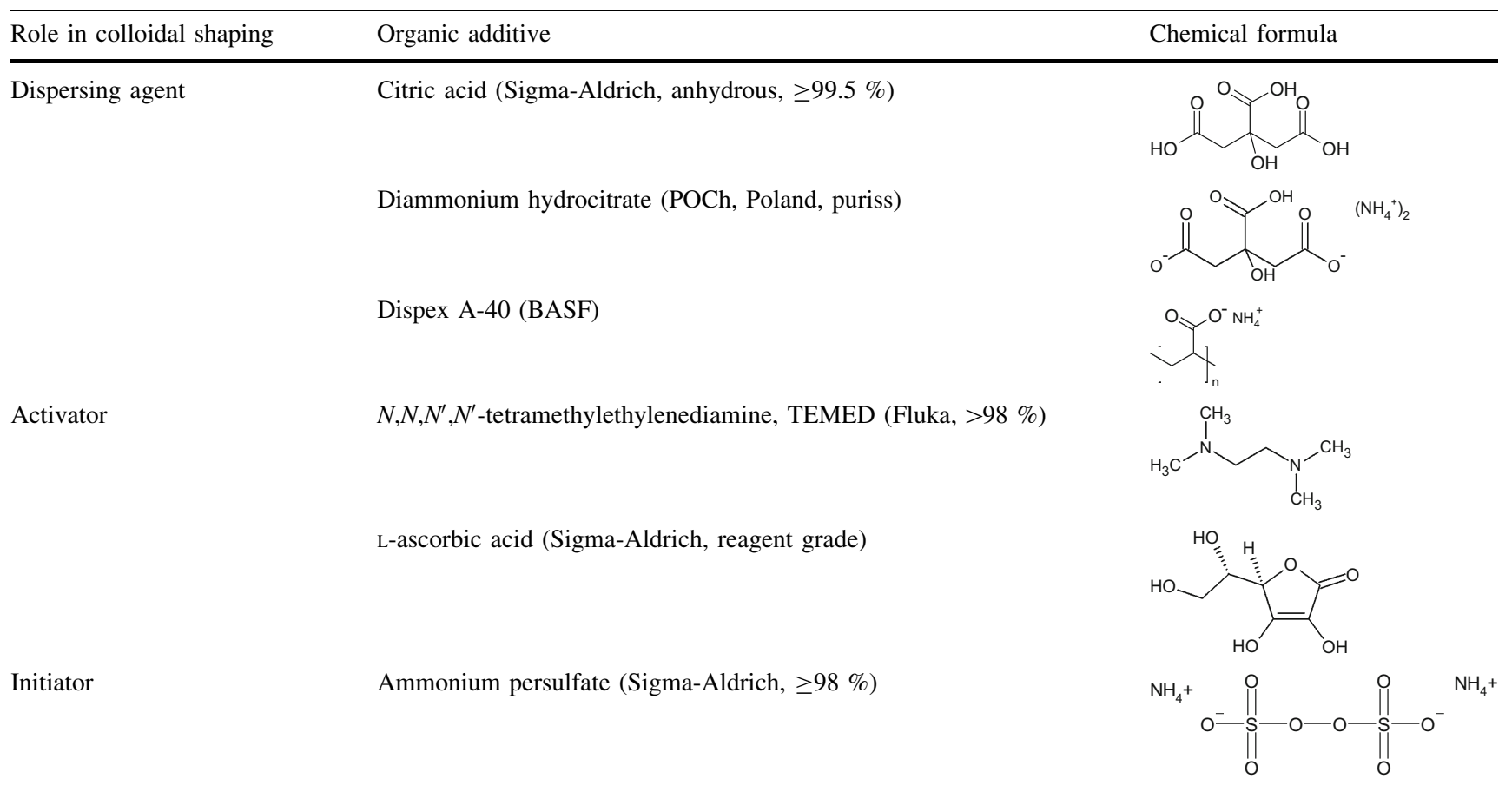


Table $2 \mathrm{~m} / \mathrm{z}$, values and their intensities for the analyzed gases

\begin{tabular}{lllllll}
\hline $\mathrm{H}_{2} \mathrm{O}$ & $\mathrm{CO}_{2}$ & $\mathrm{NO}_{2}$ & $\mathrm{~N}_{2} \mathrm{O}$ & $\mathrm{SO}_{2}$ & $\mathrm{NH}_{3}$ & $\mathrm{TEMED}$ \\
\hline $18(100 \%)$ & $44(100 \%)$ & $30(100 \%)$ & $44(100 \%)$ & $64(100 \%)$ & $17(100 \%)$ & $58(100 \%)$ \\
$17(23 \%)$ & $12(6 \%)$ & $46(37 \%)$ & $30(31 \%)$ & $48(49 \%)$ & $16(80 \%)$ & $42(7 \%)$ \\
\hline
\end{tabular}

to TG curve. Two peaks are visible on DTA curve, the endothermic peak with the minimum at $185^{\circ} \mathrm{C}$ and the wide exothermic peak with the maximum at $542{ }^{\circ} \mathrm{C}$. More information of MS curves is shown in Fig. 2. Course of curves of $\mathrm{m} / \mathrm{z}$ values 17 and 18 is similar what indicates that they correspond to $\mathrm{H}_{2} \mathrm{O}$. There is one maximum on MS 18 at $189{ }^{\circ} \mathrm{C}$ which overlap with endothermic peak on DTA at $185^{\circ} \mathrm{C}$, what indicates on dehydration process. The presence of $\mathrm{CO}_{2}$ is confirmed by $\mathrm{m} / \mathrm{z}$ values 12 and 44 . There is the increase in the intensities of MS 44 and 12 signals with the maxima at 217 and $552{ }^{\circ} \mathrm{C}$, what indicates on the decomposition of citrate ion. MS signals 30 and 46 correspond to $\mathrm{NO}_{2}$; here again two maxima at temperatures 188 and $548{ }^{\circ} \mathrm{C}$ are observed. They indicate the oxidation of ammonium groups to $\mathrm{NO}_{2}$. The maxima on MS 44 and 30 overlap with the maximum on DTA curve and is connected with $31 \%$ mass loss. Hence, degradation of diammonium hydrocitrate proceeds in two main steps and ends at ca. $659{ }^{\circ} \mathrm{C}$. The main products of decomposition in the oxidizing atmosphere are: $\mathrm{H}_{2} \mathrm{O}, \mathrm{CO}_{2}$ and $\mathrm{NO}_{2}$.

Figure 3 shows DTA/TG/DTG curves of citric acid (CA) thermal degradation. The total mass loss was $100 \%$ what indicates that the whole $\mathrm{CA}$ has decomposed. Mass loss is observed until ca. $501{ }^{\circ} \mathrm{C}$, and therefore, decomposition of $\mathrm{CA}$ ends $158{ }^{\circ} \mathrm{C}$ lower than DAC. Two main stages of CA degradation are observed; the first stage till $233{ }^{\circ} \mathrm{C}$ connected with $81 \%$ mass loss and the second stage till $501{ }^{\circ} \mathrm{C}$ with $19 \%$ mass loss. The first stage of decomposition is connected with high increase in intensities of all MS signals, that is 12, 17, 18, and 44 which corresponds to $\mathrm{H}_{2} \mathrm{O}$ and $\mathrm{CO}_{2}$ (Fig. 4). The first peak on MS 18 is wider than on MS 44 what together with the endothermic peak on DTA with the minimum at $162{ }^{\circ} \mathrm{C}$ can be ascribed to the dehydration process and partial decomposition of hydrocarbon chain. The next DTA endothermic peak with the minimum at $213{ }^{\circ} \mathrm{C}$ can be the result of the overlap of two effects: further dehydration (what indicate MS 17 and 18) and decomposition of hydrocarbon chain with the release of $\mathrm{CO}_{2}$ (what indicate MS 12 and 44). Then, further degradation of chain proceeds what is observed as a wide exothermic peak on DTA with the maximum at $458{ }^{\circ} \mathrm{C}$, a small peak on MS 18 with the maximum at $361{ }^{\circ} \mathrm{C}$ and two peaks of smaller intensities on MS 44 with maxima at 370 and $452{ }^{\circ} \mathrm{C}$.

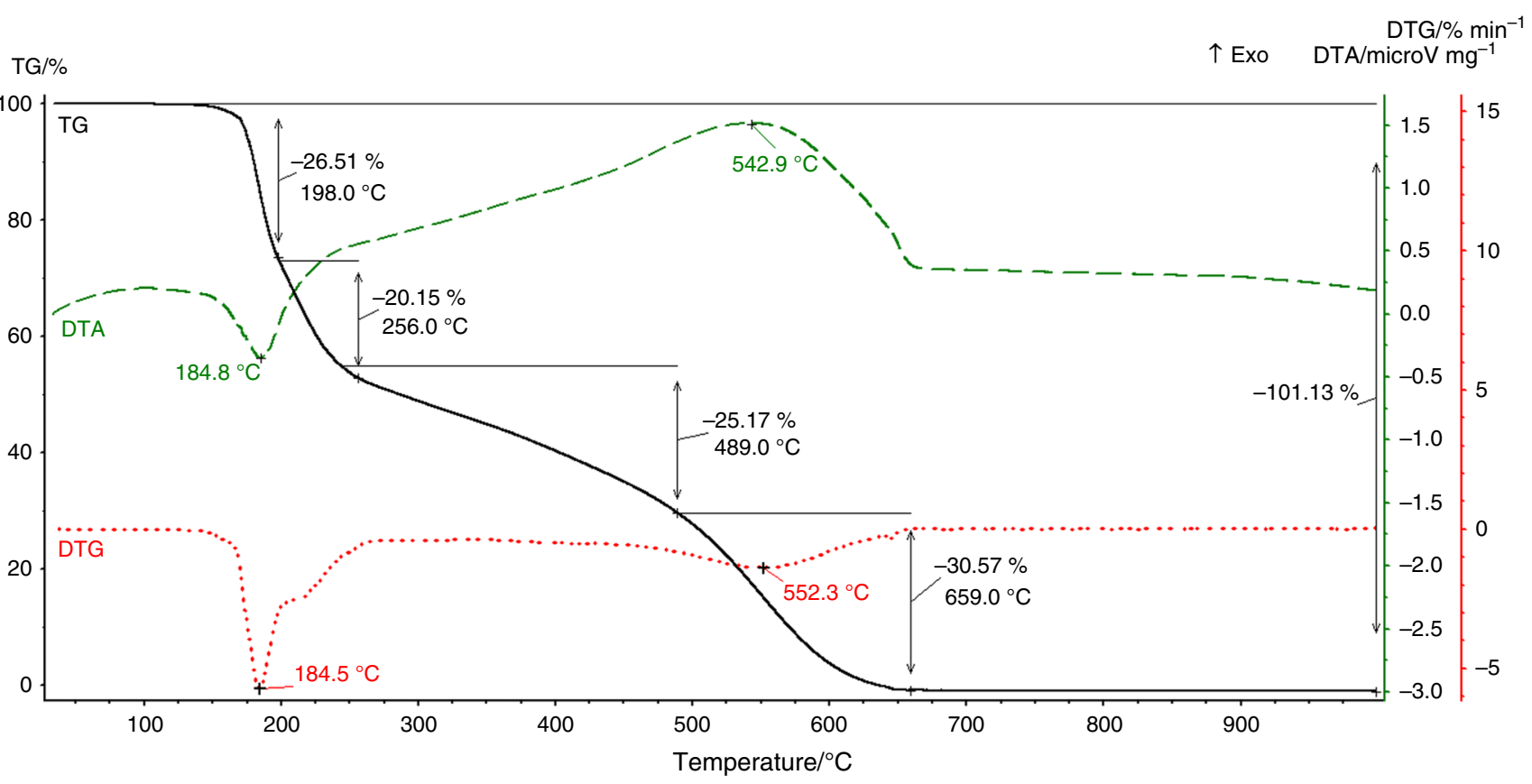

Fig. 1 DTA/TG/DTG curves of diammonium hydrocitrate 


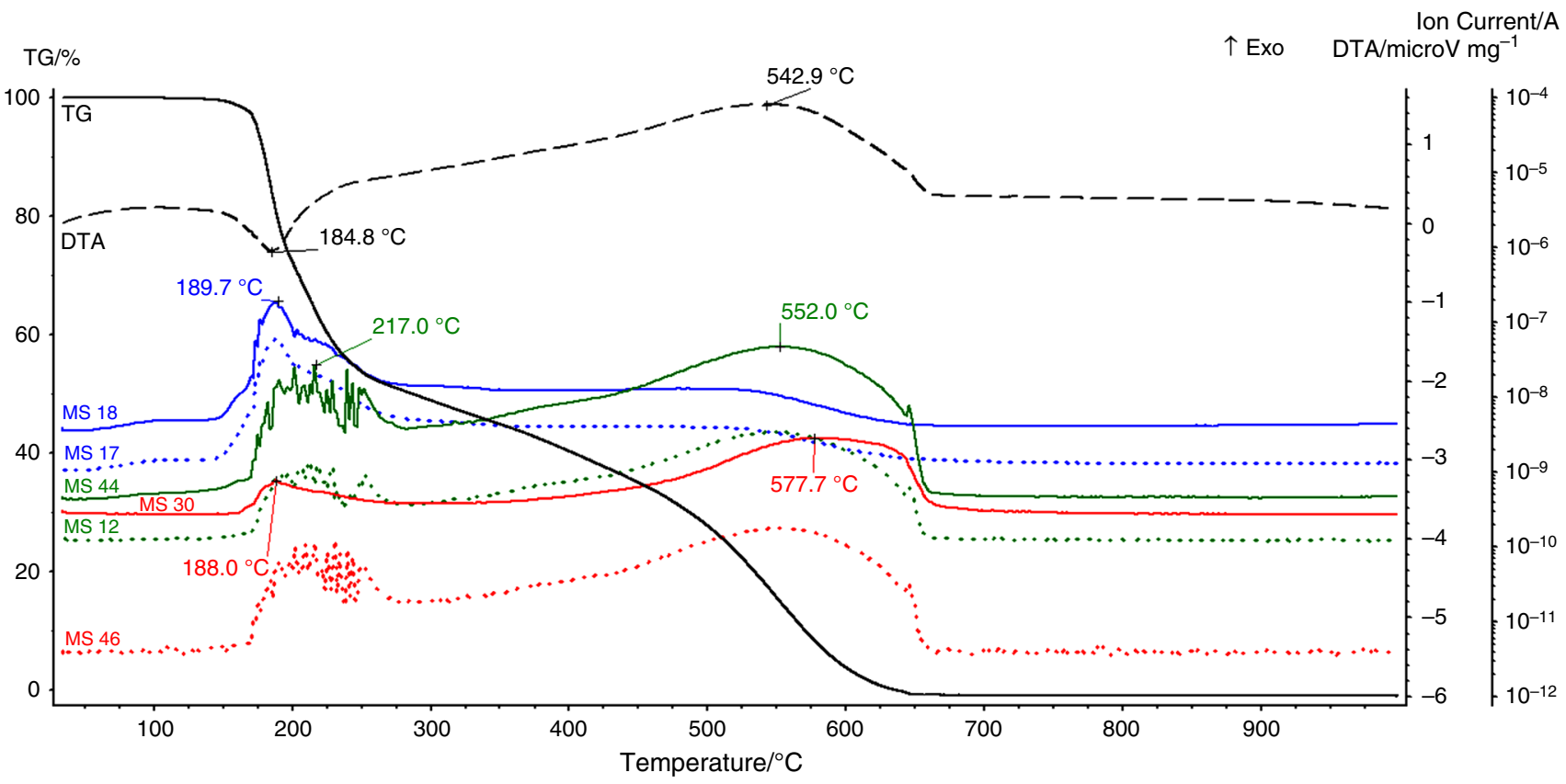

Fig. 2 MS analysis of diammonium hydrocitrate during heating

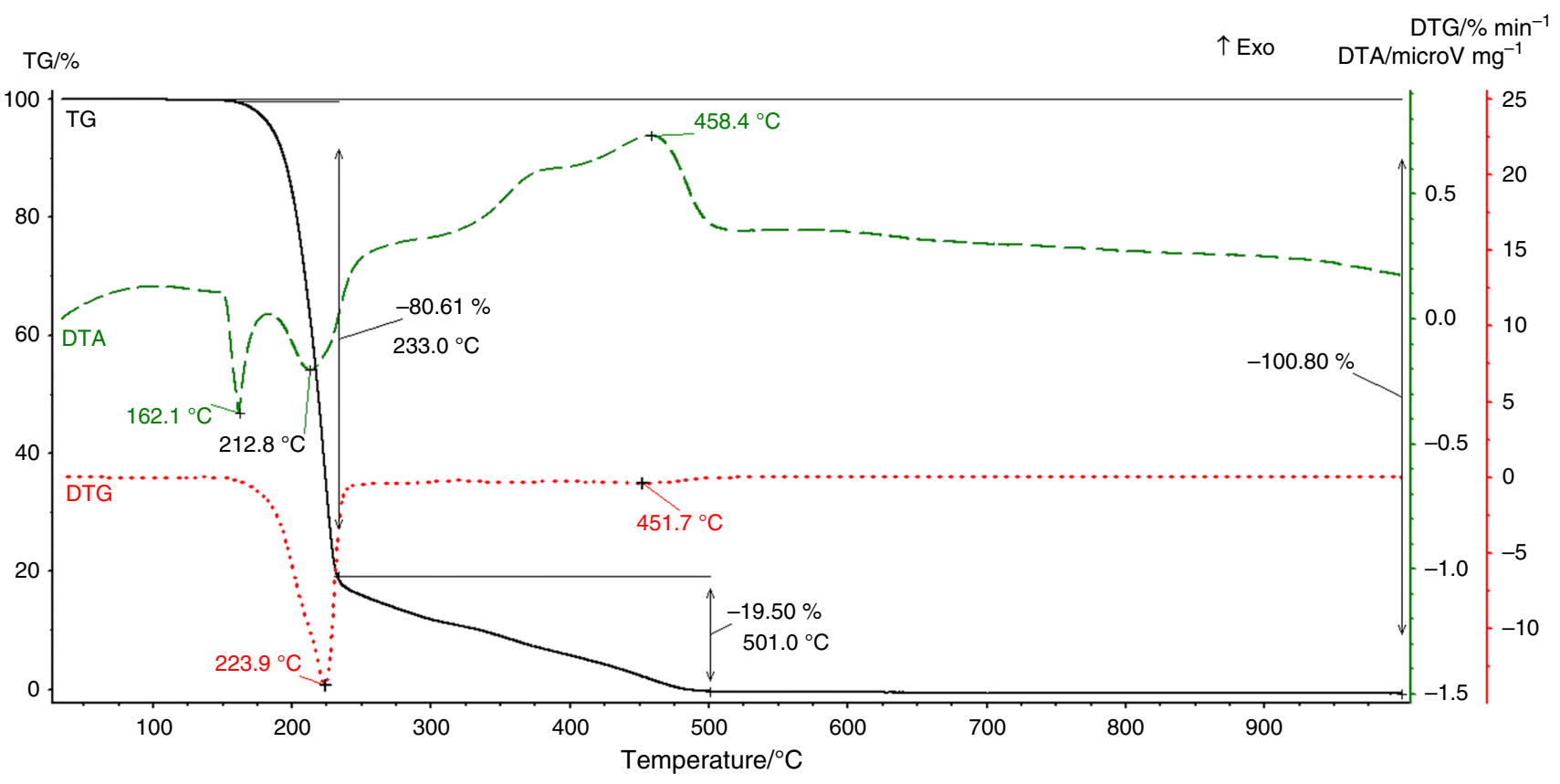

Fig. 3 DTA/TG/DTG of citric acid

Comparing the obtained results with the available literature, it can be underlined that the decomposition of citric acid is not a single-step process. The measurements performed in argon atmosphere allowed Wyrzykowski et al. [23] to propose the thermal transformation pattern of the citric acid showing the intermediate products, such as trans-aconitic acid and citraconic anhydride. It was summarized that thermal decomposition is a complex process leading through dehydration and decarboxylation. Reda [24] examined the thermal stability of selected antioxidants, including citric acid and ascorbic acid. His measurements were performed under the following conditions: heating rate of $20{ }^{\circ} \mathrm{C} \mathrm{min}{ }^{-1}$ in an atmosphere of

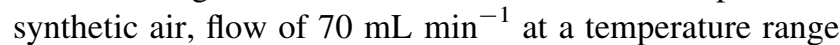




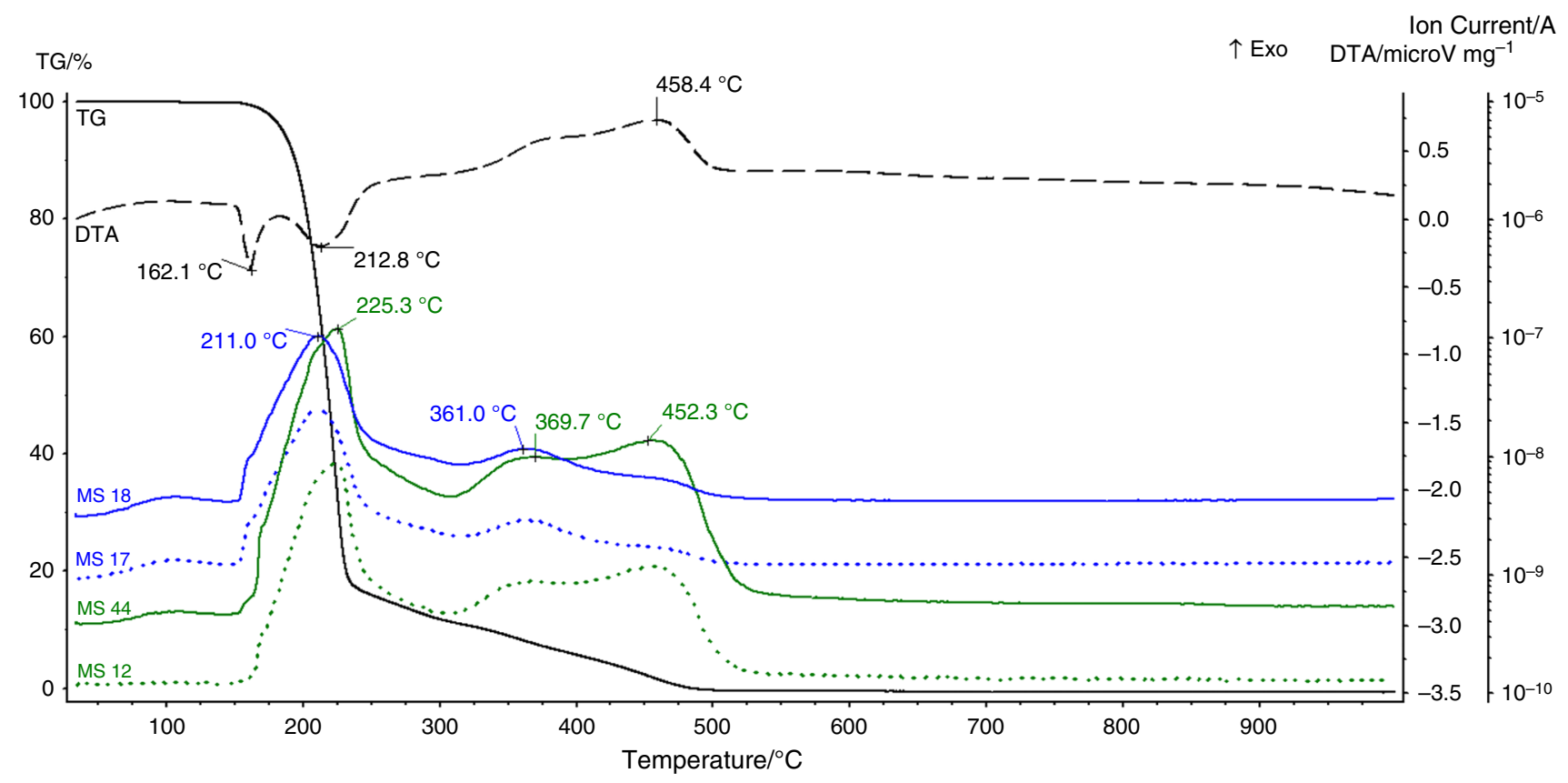

Fig. 4 MS analysis of citric acid during heating

of $25-600{ }^{\circ} \mathrm{C}$. According to his measurements, decomposition of citric acid starts above $160{ }^{\circ} \mathrm{C}$, culminating at around $220^{\circ} \mathrm{C}$, what is in a good agreement with the results presented in this paper. Moreover, in case of ascorbic acid, decomposition of the antioxidant starts at around $190{ }^{\circ} \mathrm{C}$ what again is the similar result to that obtained within the measurements described below.

Thermal analysis of citric acid degradation gives the important information that the main step of decomposition which is connected with the release of high quantities of gases goes till ca. $233{ }^{\circ} \mathrm{C}$. For this reason, it is preferable to conduct the sintering process of ceramic samples prepared with the use of citric acid with a low heating rate (for example $1{ }^{\circ} \mathrm{C} \mathrm{min}-1$ ) at low temperatures. Too fast heating till $233{ }^{\circ} \mathrm{C}$ may result in rapid release of cumulated gases and therefore crack appearance in the ceramic body. Sintering of ceramic samples at different heating rates has been already examined by author; the obtained results showed that heating rate equaling $5{ }^{\circ} \mathrm{C} \mathrm{min}{ }^{-1}$ resulted in the creation of pores in the sample, what was observed on the SEM images [22].

Figure 5 shows DTA/TG/DTG curves of thermal degradation of an ammonium salt of an acrylic polymer in water (Dispex A-40). The total mass loss was $99 \%$ what indicates that the whole Dispex A-40 has decomposed. Mass loss is observed until ca. $599^{\circ} \mathrm{C}$. Several stages of Dispex degradation are observed. The first stage till $131{ }^{\circ} \mathrm{C}$ is connected with $56 \%$ mass loss, and then two stages till 187 and $291{ }^{\circ} \mathrm{C}$ with ca. $6 \%$ mass loss are observed. The last two stages of thermal decomposition till temperatures
392 and $599{ }^{\circ} \mathrm{C}$ are connected with 14 and $16 \%$ mass loss, respectively. The first stage of decomposition is connected with DTA endothermic peak with the minimum at $118{ }^{\circ} \mathrm{C}$ and MS signals 17, $18\left(\mathrm{H}_{2} \mathrm{O}\right)$ and 12, $44\left(\mathrm{CO}_{2}\right)$ (Fig. 6). The assumption that $\mathrm{CO}_{2}$ not $\mathrm{N}_{2} \mathrm{O}$ is released at this stage of decomposition is based on the fact that there is a visible peak on MS 12, while MS 30 curve is flat. The increase in MS 30 signal is observed at $160{ }^{\circ} \mathrm{C}$, but the presence of MS 46 signal indicates that $\mathrm{NO}_{2}$ is released at higher temperatures. It must be also mentioned that in case of ammonium salt of an acrylic polymer, ammonia is released from the compound at low temperatures, and for this reason, mass loss on TG curve is observed from the very beginning of the analysis. As explained later for ammonium persulfate decomposition, it is difficult to distinguish $\mathrm{NH}_{3}$ in the conditions of the measurement. At temperature $196{ }^{\circ} \mathrm{C}$, the peaks on MS curves 18 and 17 accompanied by $6 \%$ mass loss are observed what can be ascribed to dehydration of the sample. The next decomposition stages are connected with two exothermic peaks on DTA at 379 and $540{ }^{\circ} \mathrm{C}$, accompanied by the increase in MS signals $12,18,30,44$, and 46. This indicates that during decomposition of Dispex A-40 at temperature range $291-599{ }^{\circ} \mathrm{C}, \mathrm{H}_{2} \mathrm{O}, \mathrm{CO}_{2}$, and $\mathrm{NO}_{2}$ are released to the atmosphere. The stepped mass loss and the presence of a few maxima on MS curves indicate that thermal decomposition of the polymeric chains proceeds gradually. According to the literature, in case of thermal degradation of acrylic polymers in nitrogen atmosphere, the major decomposition products comes from main chain scission, giving monomers, dimers, saturated 


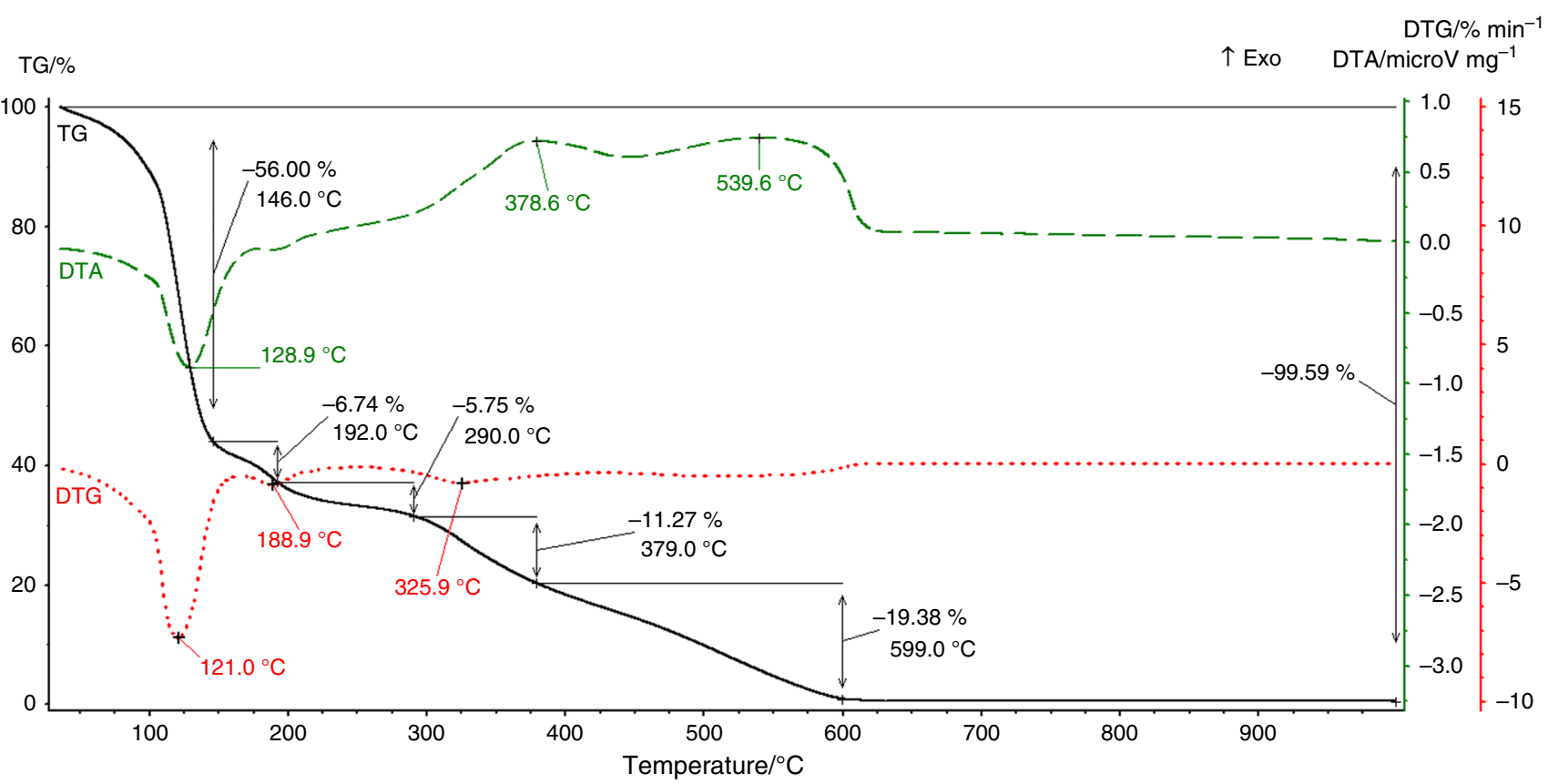

Fig. 5 DTA/TG/DTG of dispex A-40

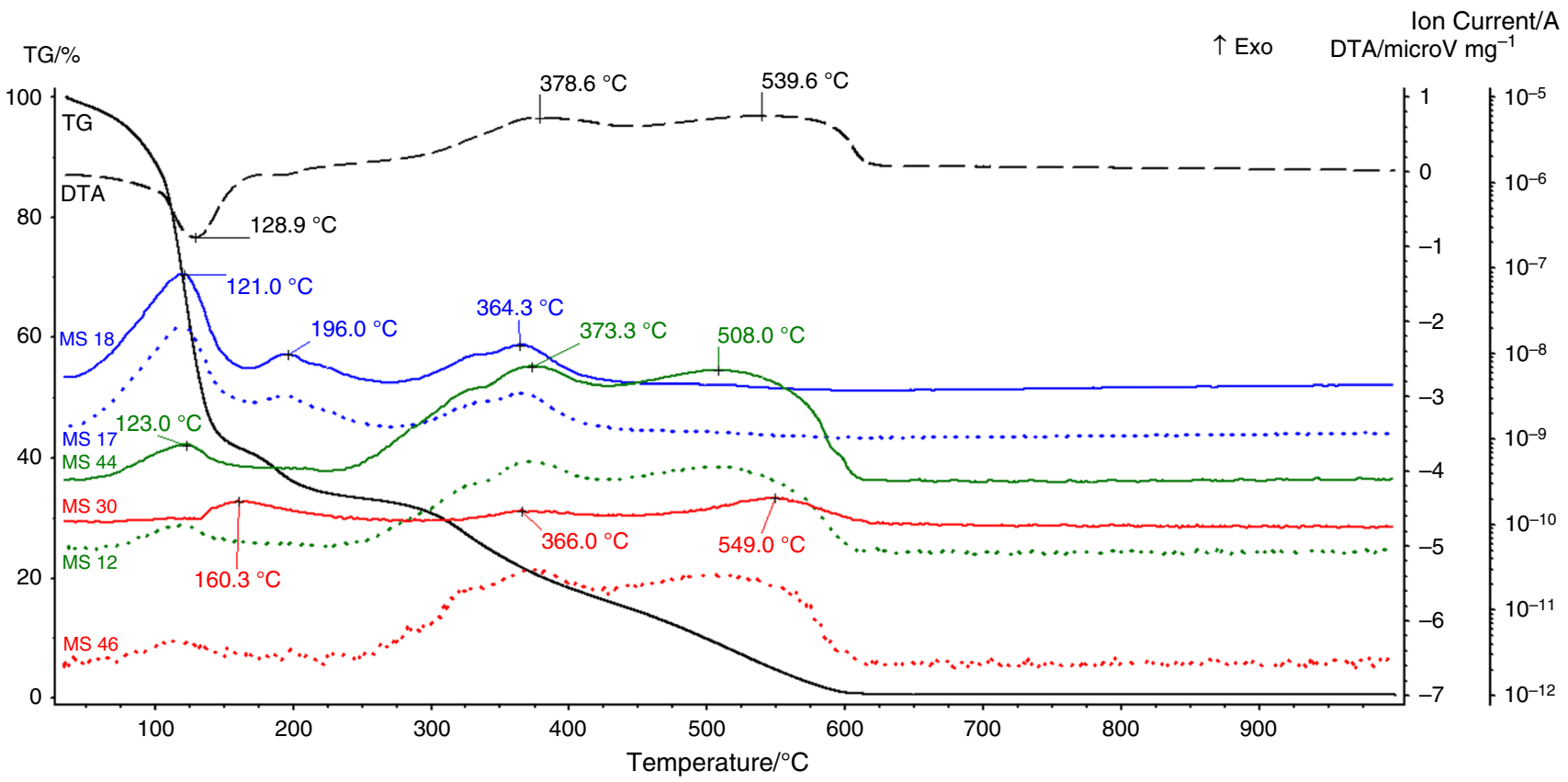

Fig. 6 MS analysis of dispex A-40 during heating

diesters, and trimers. The light products of decomposition include also carbon dioxide and water [25]. In case of the research carried out in air atmosphere, the oxidation of intermediate products proceeds and light gases are released.

The most commonly used system for initiating of polymerization reaction in ceramic technology is a redox system. It is based on two substances, activator (catalyst) and initiator, where due to redox reaction free radicals are created which initiate the polymerization process. In scientific literature, the most commonly used redox system in ceramic processing is $N, N, N^{\prime}, N^{\prime}$-tetramethylethylenediamine (TEMED) and ammonium persulfate (APS) [26, 27]. Nevertheless, there appears information concerning the use 
of L-ascorbic acid (L-AA) instead of harmful TEMED [28]. For these reasons, the presented below diagrams concern the thermal analysis of TEMED, L-AA and APS decomposition. The TG curve presented in Fig. 7 indicates that the total degradation of TEMED proceeds till $135^{\circ} \mathrm{C}$, and the mass loss begins at room temperature. The degradation is connected with the release of several gaseous products which have been detected by mass spectrometer (Fig. 8). There is only one peak visible on each MS curve at temperature ca. $131{ }^{\circ} \mathrm{C}$. The $\mathrm{m} / \mathrm{z}$ values detected by mass spectrometer are as follows: 17, $18\left(\mathrm{H}_{2} \mathrm{O}\right), 12,44\left(\mathrm{CO}_{2}\right)$, 30, $46\left(\mathrm{NO}_{2}\right)$, and 58, 42 (TEMED). MS 58 and 42 may indicate on the release of TEMED vapors. Moreover, $\mathrm{m} /$ $z 17$ can correspond to $\mathrm{NH}_{3}$, but as in the case of DAC and APS, the confirmation of this statement is not obvious in the conditions of the measurement. The analysis showed that thermal decomposition of TEMED is the one-stage rapid process connected with the release of high amounts of gaseous products. This information is very important from technological point of view because during both polymerization and drying of ceramic samples, TEMED can begin to decompose at temperatures below $100{ }^{\circ} \mathrm{C}$.

Figure 9 shows DTA/TG/DTG curves of L-ascorbic acid (L-AA) thermal degradation. The total mass loss was $100 \%$ what as in case of previous substances indicates that the whole acid has decomposed. Mass loss is observed until ca. $574{ }^{\circ} \mathrm{C}$. Three main stages of L-AA degradation are observed; the first stage till $232{ }^{\circ} \mathrm{C}$ connected with $32 \%$ mass loss, the second stage till $346{ }^{\circ} \mathrm{C}$ with $28 \%$ mass loss, and the third stage till $574{ }^{\circ} \mathrm{C}$ with $40 \%$ mass loss.
The highest intensities of MS signals (of $m / z$ values 12,17 , 18 and 44) are observed in temperature range $217-221^{\circ} \mathrm{C}$ and are connected with the DTA endothermic peak at $202{ }^{\circ} \mathrm{C}$ (Fig. 10). This can indicate on dehydration process and partial decomposition of the compound. Then the intensities of MS signals slightly decrease, but still $\mathrm{H}_{2} \mathrm{O}$ and $\mathrm{CO}_{2}$ are released from the sample. Two exothermic maxima can be observed at $343{ }^{\circ} \mathrm{C}$ (MS 18 and 44) and at $504{ }^{\circ} \mathrm{C}$ (MS 44). The course of DTA curve overlap with the MS 12 and 44 curves in temperature range $232-574{ }^{\circ} \mathrm{C}$ what indicates the gradual decomposition of ring and aliphatic substituent. It is worth to compare the products of thermal degradation of two activators of polymerization, which are TEMED and L-AA. Due to the chemical constitution of TEMED, $\mathrm{NO}_{2}$ and probably ammonia are released during its burnout, while L-AA is environmentally friendly compound, and only $\mathrm{CO}_{2}$ and $\mathrm{H}_{2} \mathrm{O}$ are the gaseous products which go to the atmosphere.

The last analyzed compound was ammonium persulfate (APS). Plots of DTA/TG/DTG and MS are presented in Figs. 11 and 12. Here, thermal degradation is a much more complicated process than in case of previous substances. The total mass loss was $99 \%$ what indicates that the whole salt has decomposed. However, mass loss is observed till $920{ }^{\circ} \mathrm{C}$, which is ca. $400{ }^{\circ} \mathrm{C}$ higher than in case of other analyzed compounds. The thermally activated decomposition of persulfate ion leads to the formation of sulfate radical ion [29], which then can be oxidized to $\mathrm{SO}_{2}$, as shown on MS spectra. In parallel, ammonia may be released at lower temperatures, but then oxidation process

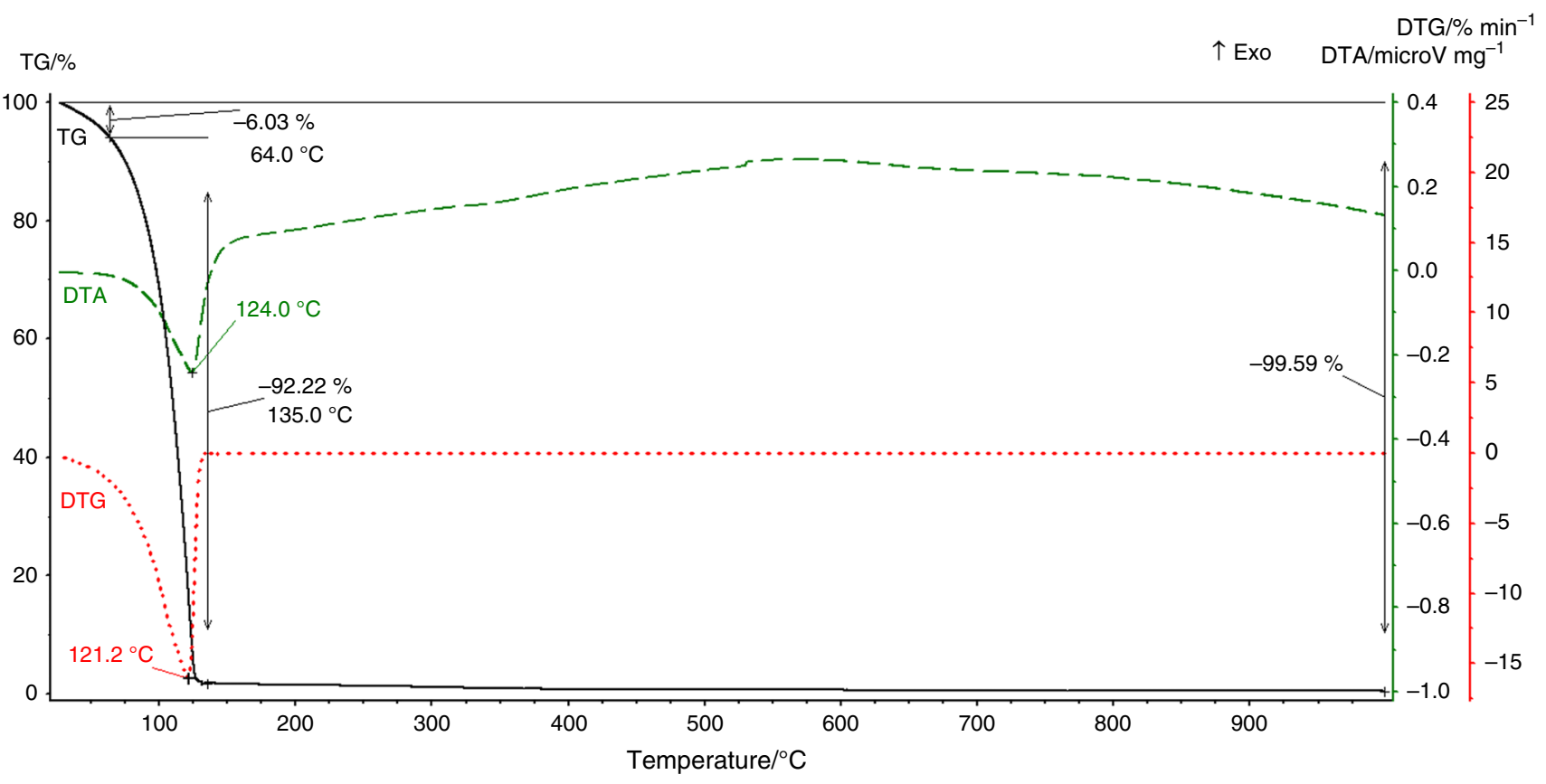

Fig. 7 DTA/TG/DTG of $N, N, N^{\prime}, N^{\prime}$-tetramethylethylenediamine 


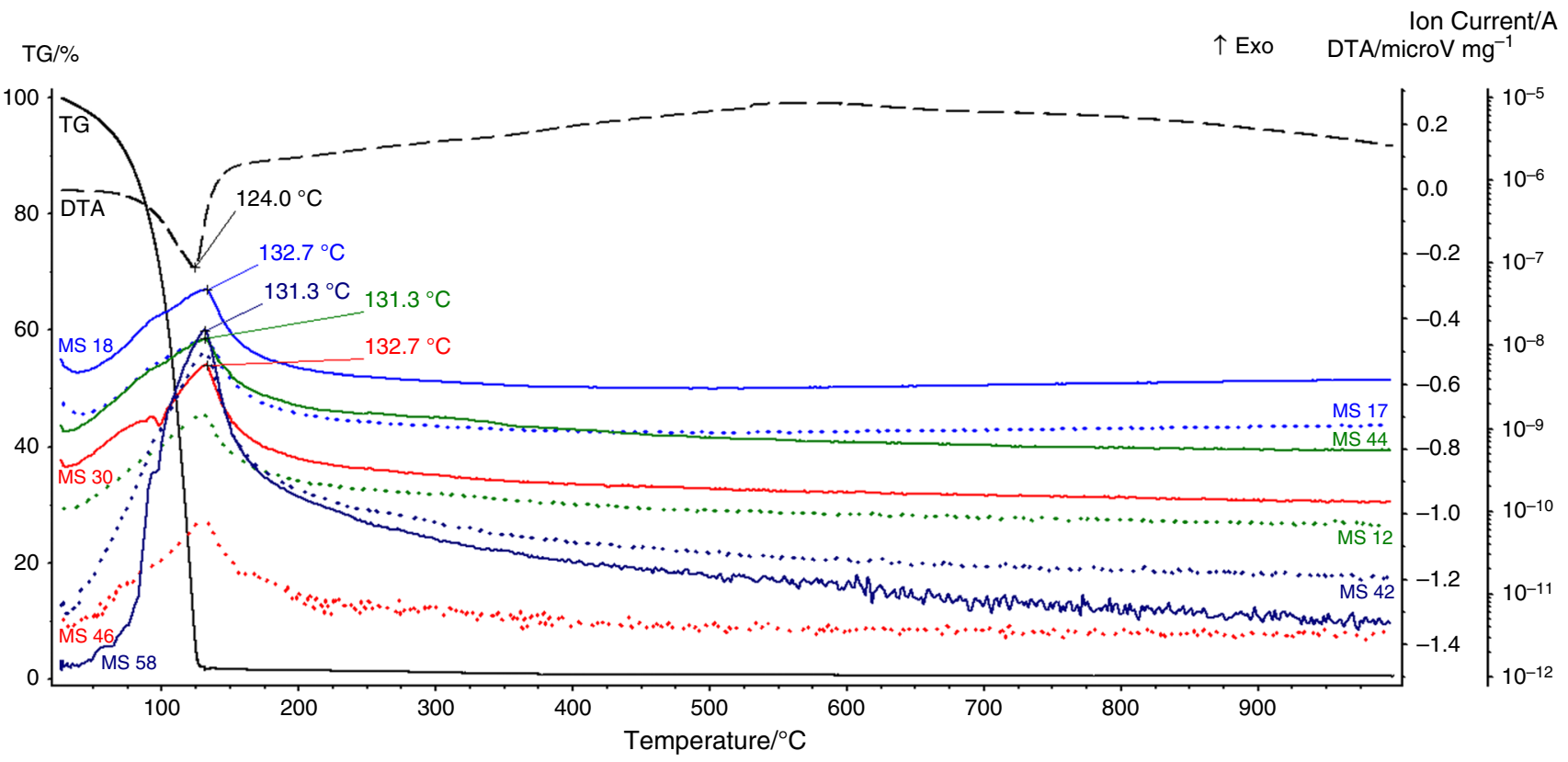

Fig. 8 MS analysis of $N, N, N^{\prime}, N^{\prime}$-tetramethylethylenediamine during heating

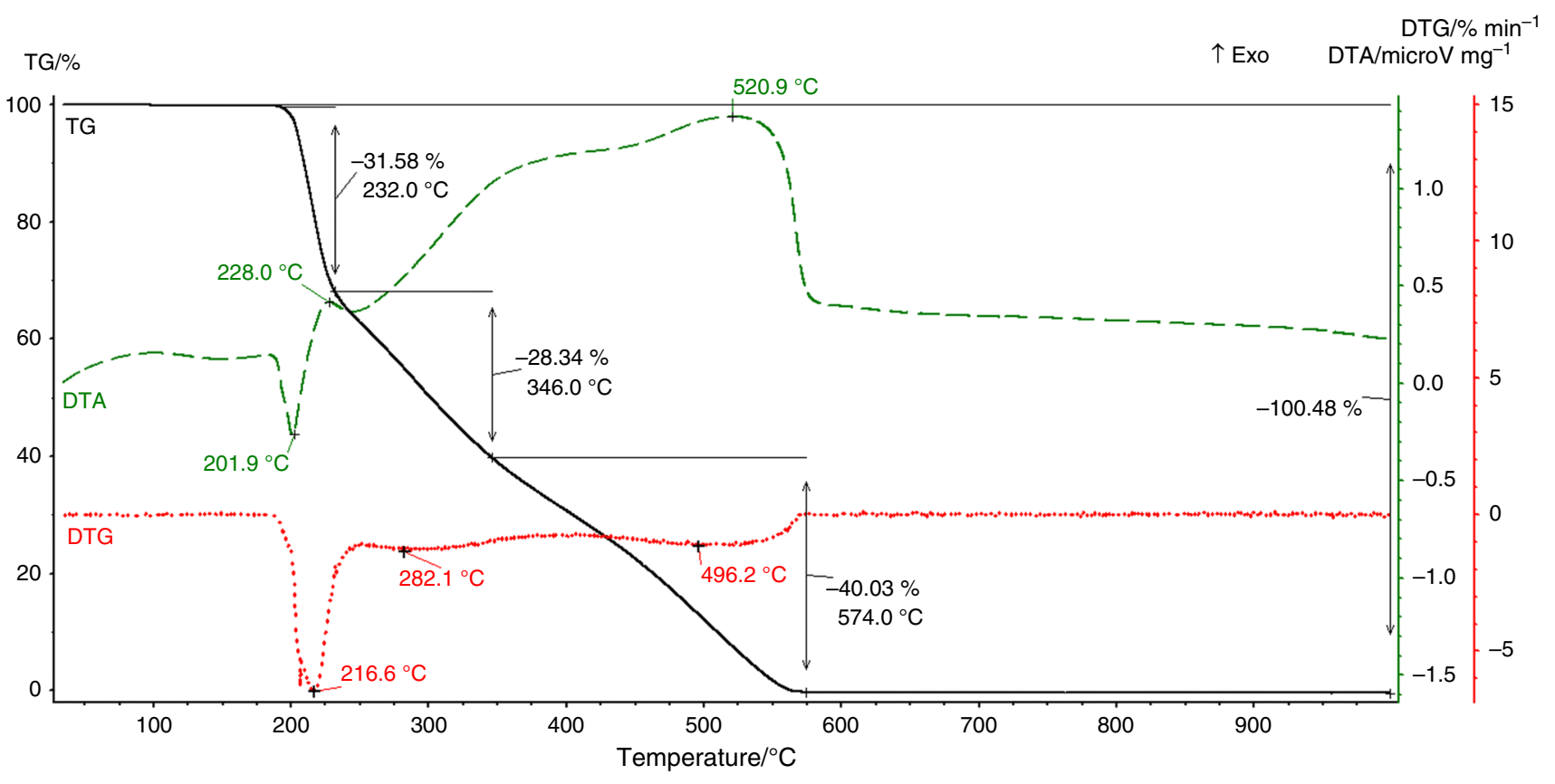

Fig. 9 DTA/TG/DTG of L-ascorbic acid

begins and as a result $\mathrm{NO}_{2}$ appears. At the beginning, three decomposition steps, accompanied by a small mass loss, are observed. The first stage till $202{ }^{\circ} \mathrm{C}$ with $7 \%$ mass loss is connected with DTA exothermic peak. In this temperature region, MS signals of $\mathrm{m} / z$ values 44 and 30 are observed (maxima at 192 and $223{ }^{\circ} \mathrm{C}$ ). In case of APS, $\mathrm{m} / \mathrm{z}$ value 44 may correspond to $\mathrm{N}_{2} \mathrm{O}$. The second characteristic mass for nitrogen monoxide is 30 , but this mass corresponds also to $\mathrm{NO}_{2}$. It is therefore probable that $\mathrm{N}_{2} \mathrm{O}$ is the product of thermal degradation of APS, but in air atmosphere, it oxidizes to $\mathrm{NO}_{2}$. No peaks on MS 18 are observed in this temperature. The little peak on MS 18 at $99{ }^{\circ} \mathrm{C}$ can be ascribed to moisture evaporation from the sample. The second stage of APS decomposition till $304{ }^{\circ} \mathrm{C}$ with $3 \%$ mass loss is also connected with DTA exothermic peak, but here mass spectrometer detected $\mathrm{m} /$ 


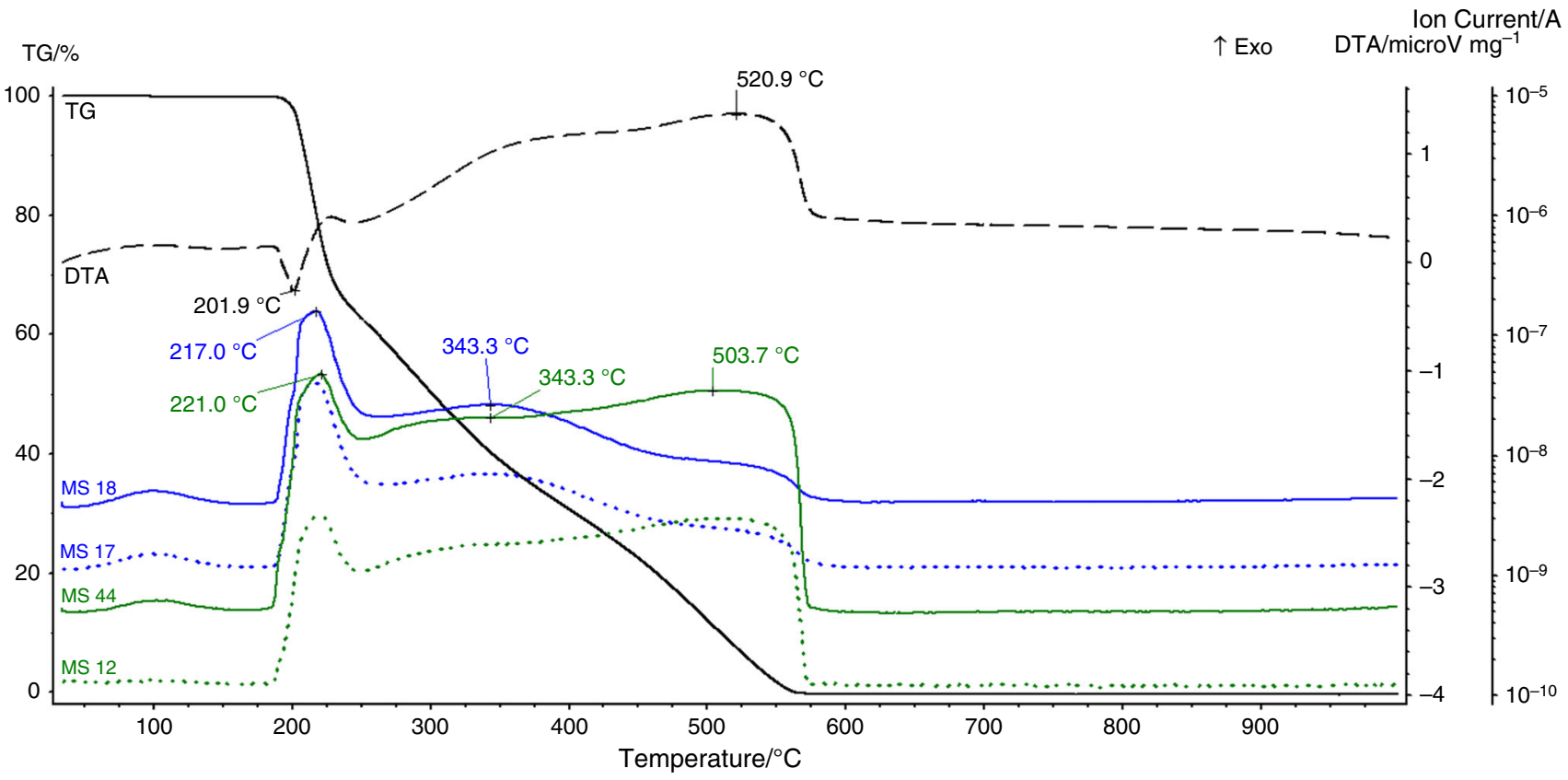

Fig. 10 MS analysis of L-ascorbic acid during heating

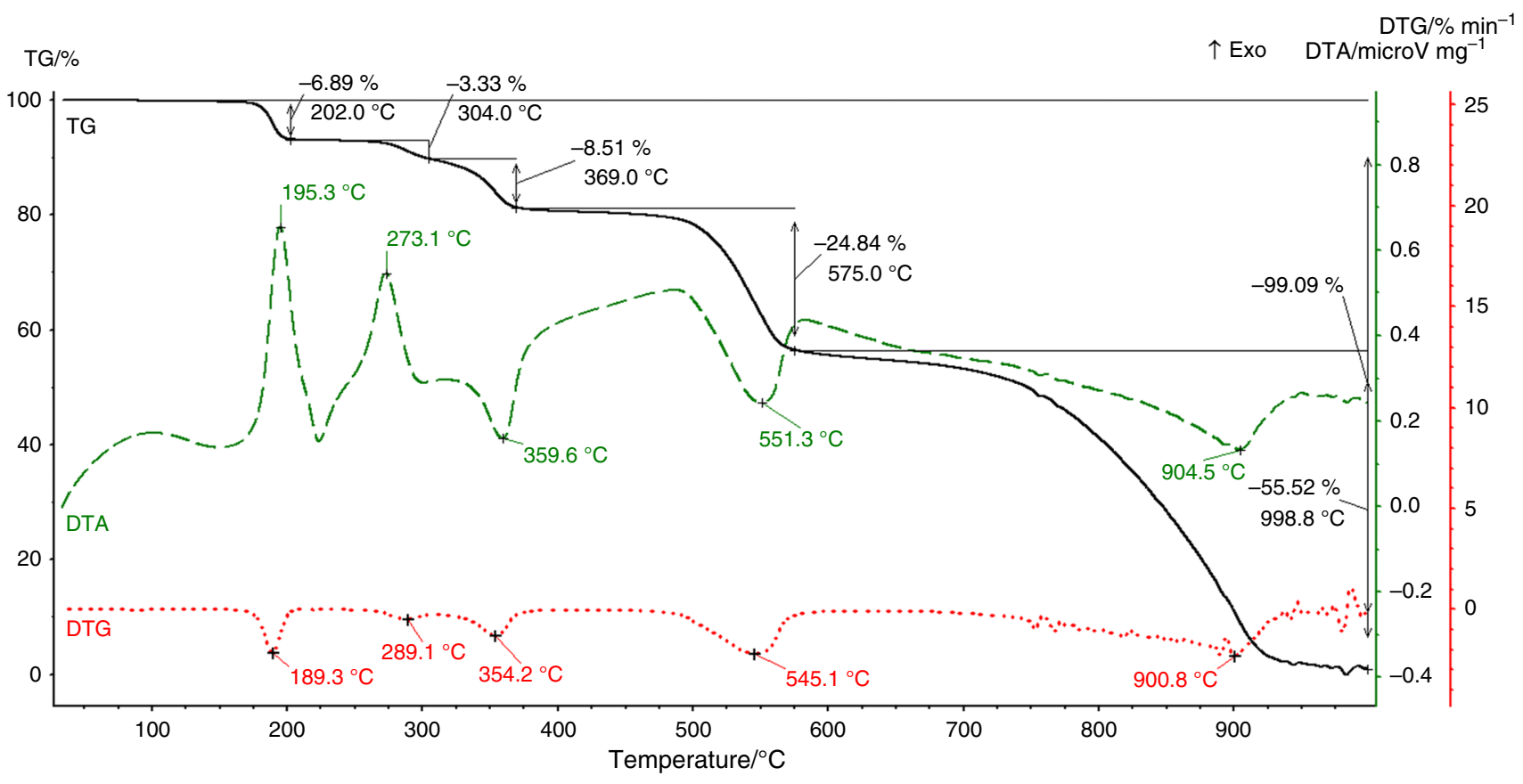

Fig. 11 DTA/TG/DTG of ammonium persulfate

$z$ values 18,44 , and 30 which can be ascribed to $\mathrm{H}_{2} \mathrm{O}, \mathrm{N}_{2} \mathrm{O}$, and $\mathrm{NO}_{2}$. The third stage of APS degradation till $369^{\circ} \mathrm{C}$ with $9 \%$ mass loss is connected with DTA endothermic peak. According to mass spectrometer, $\mathrm{H}_{2} \mathrm{O}$ and $\mathrm{NO}_{2}$ seem to be the dominant gases, while concentration of $\mathrm{N}_{2} \mathrm{O}$ is smaller. It must be noticed that MS signal 17 in this region has slightly higher intensity than MS 18. It might mean that
$\mathrm{NH}_{3}$ is released; nevertheless, it is difficult to confirm it in these measurement conditions. The second characteristic $\mathrm{m} / \mathrm{z}$ value for ammonia is 16 , but this is also the $\mathrm{m} / \mathrm{z}$ of $\mathrm{O}_{2}$, and the flow of air was $60 \mathrm{~mL} \mathrm{~min}^{-1}$. It means that the intensity of MS 16 is about two orders of magnitude higher than MS 17 or 18, what makes it impossible to distinguish any changes on MS 16 connected with eventual release of 


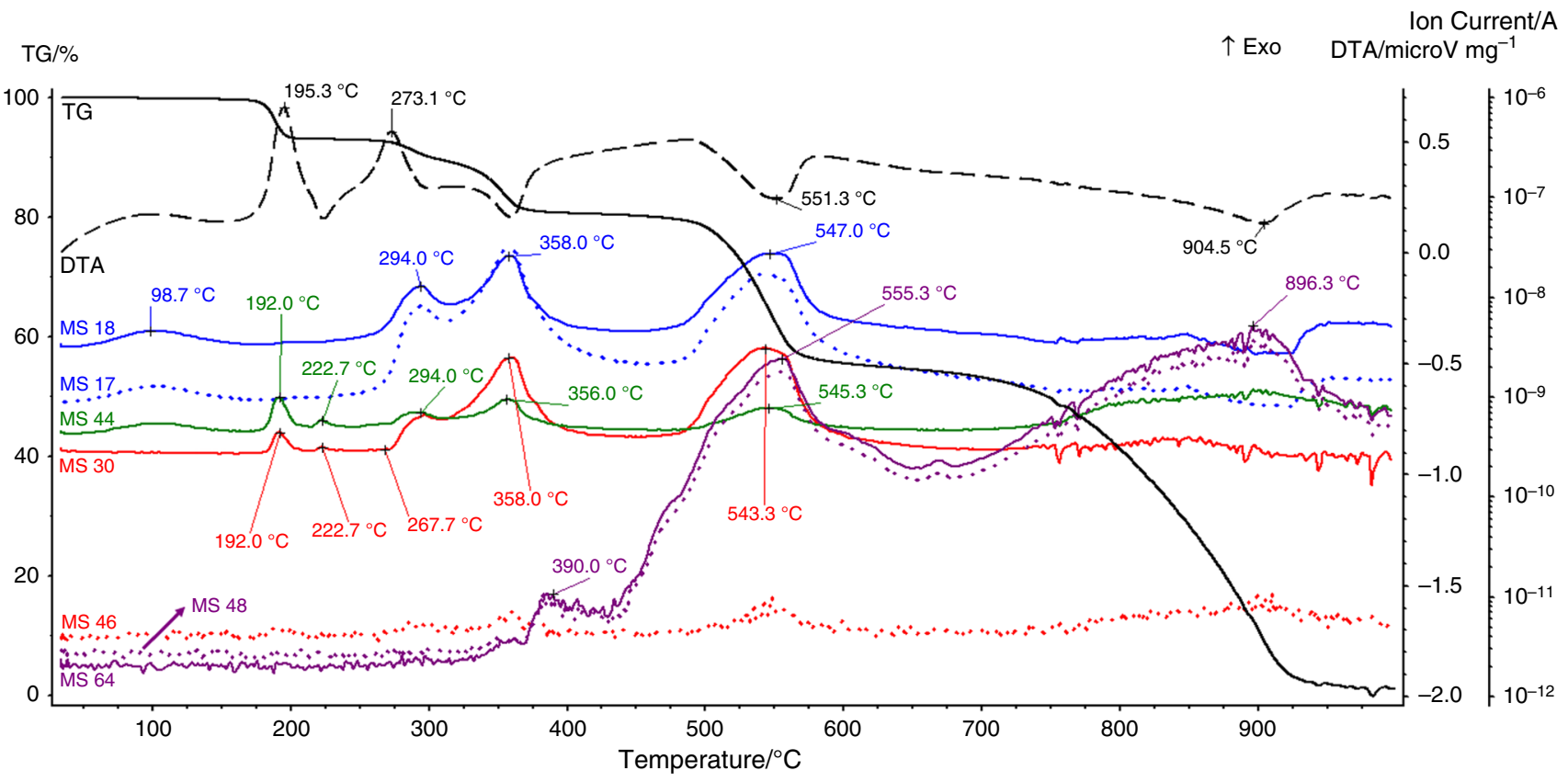

Fig. 12 MS analysis of ammonium persulfate during heating

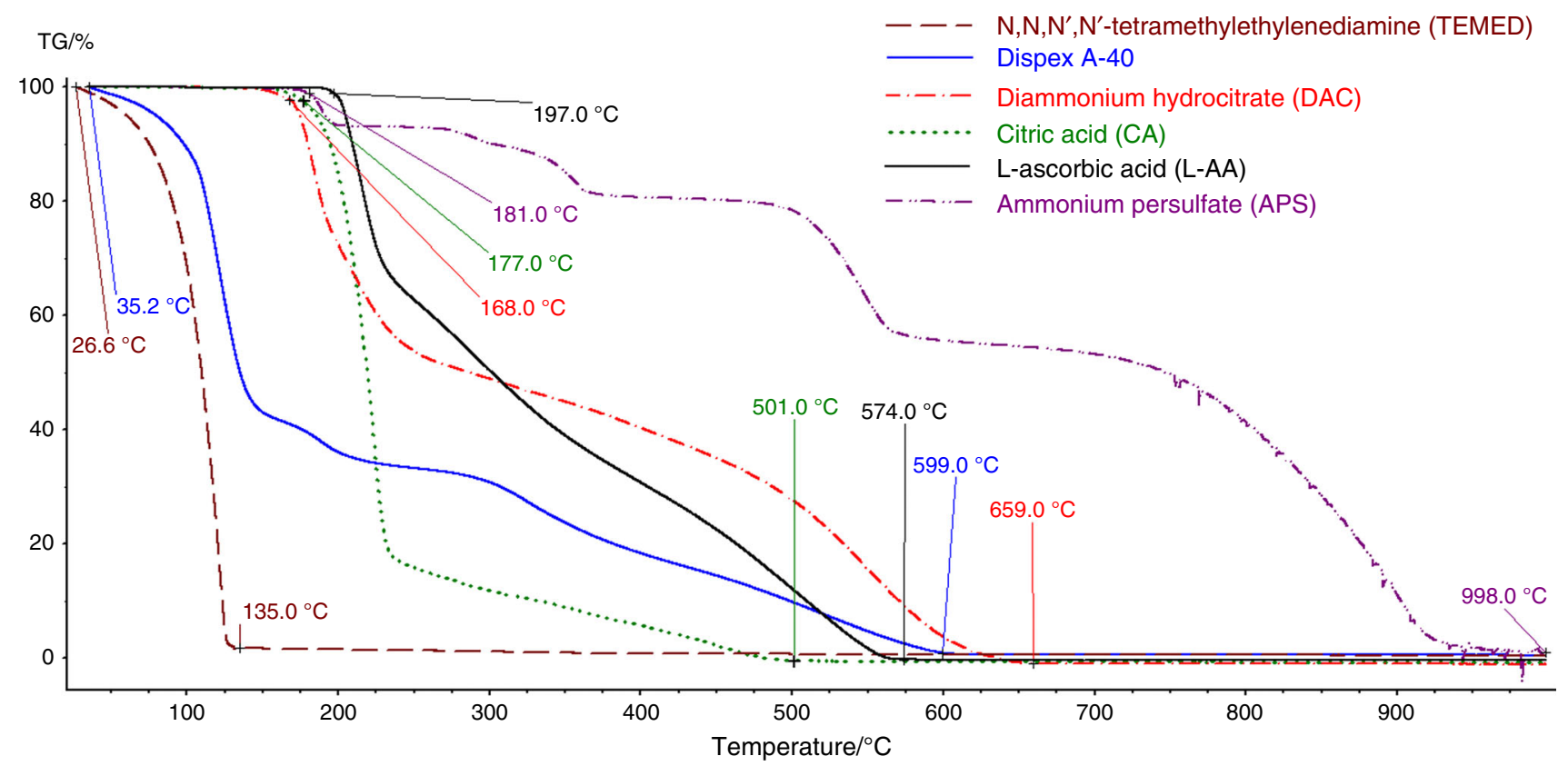

Fig. 13 TG curves of all investigated substances

$\mathrm{NH}_{3}$. Running the experiment in non-oxidizing atmosphere would lead to completely different decomposition mechanism, and different gaseous products would be released, what might be very interesting form scientific point of view but non-applicable in case of conventional sintering of ceramics. The next decomposition stage appears in temperature $545{ }^{\circ} \mathrm{C}$ with $25 \%$ mass loss. Here, the intensities of many MS signals are increased: $12,17,18,30,46,48$, and 64, what can be ascribed to the following gases: $\mathrm{H}_{2} \mathrm{O}$ (and $\mathrm{HN}_{3}$ ), $\mathrm{N}_{2} \mathrm{O}, \mathrm{NO}_{2}$, and $\mathrm{SO}_{2}$. The dominant gaseous product is $\mathrm{SO}_{2}$. The increase in the temperature till $920{ }^{\circ} \mathrm{C}$ results in the decrease in most of the gaseous products, but the presence of $\mathrm{SO}_{2}$ is still observed which means that oxidation of sulfate ions present in APS requires high 
energy. According to TG, the mass loss within temperature range $575-1000{ }^{\circ} \mathrm{C}$ is $56 \%$. It means that the main degradation stage occurs at high temperature. This is again the very important information in case of sintering of ceramic samples prepared with the use of APS. It seems that in case of ceramic samples prepared with the use of APS, heating rate should be low till $920{ }^{\circ} \mathrm{C}$ in order to avoid cracks. In fact, the quantities of APS used in colloidal shaping of ceramics usually amount to $0.01-0.3$ mass \% with respect to ceramic powder. For this reason, the risk that cracks would appear as a result of the release of high amounts of gases during APS decomposition is small. Therefore, sintering conditions for samples containing APS should be matched individually depending on shaping method and APS concentration. Finally, it seems that gaseous products released to the atmosphere during thermal degradation of APS are the most harmful in comparison with other analyzed substances. On the other hand, APS is not as irritant as for example TEMED. It must be then summarized that both toxicity of a compound and its thermal decomposition should be taken into account when environmental aspects are concerned.

Figure 13 presents cumulative diagram of TG curves of all investigated substances. It can be concluded that the fastest thermal decomposition was observed for TEMED. Nevertheless, both TEMED and Dispex A-40 has begun to decompose at room temperature. The other four substances required raised temperature in order to start to decompose. Diammonioum hydrocitrate starts to decompose at $168^{\circ} \mathrm{C}$, but the process ends at $659{ }^{\circ} \mathrm{C}$ which means that among investigated substances, DAC is the second, after ammonium persulfate, long-degradable substance. Citric acid decomposes quite fast, in temperature range $177-501{ }^{\circ} \mathrm{C}$. L-ascorbic acid remains stable till $197^{\circ} \mathrm{C}$, and its thermal decompositions ends at $574{ }^{\circ} \mathrm{C}$. The longest and the most complicated thermal degradation was observed for ammonium persulfate; TG curve indicates mass loss till $920{ }^{\circ} \mathrm{C}$.

\section{Conclusions}

Thermal decomposition of six selected organic additives, which are commonly used in shaping of ceramic materials by colloidal methods have been performed. Three dispersing agents, two activators, and one initiator of radical polymerization have been analyzed. The fastest thermal decomposition was observed for TEMED (activator of polymerization). The process has begun at room temperature and ended at $135^{\circ} \mathrm{C}$. According to MS analysis, decomposition was followed by the release of $\mathrm{H}_{2} \mathrm{O}, \mathrm{CO}_{2}$, $\mathrm{NO}_{2}$, and probably $\mathrm{NH}_{3}$. The multi-step thermal decomposition process was observed for ammonium persulfate with the release of $\mathrm{H}_{2} \mathrm{O}, \mathrm{N}_{2} \mathrm{O}, \mathrm{NO}_{2}$ and $\mathrm{SO}_{2}$. The most environmentally friendly substances in terms of gases released to the atmosphere were citric and L-ascorbic acids. Here, the mass spectrometer has detected $\mathrm{m} / \mathrm{z}$, values only for $\mathrm{H}_{2} \mathrm{O}$ and $\mathrm{CO}_{2}$. Thus, the couple of DTA/TG with mass spectrometry is a very useful tool for analysis of thermal decomposition of different substances.

Acknowledgements This work has been financially supported by the National Science Centre of Poland (Grant No. 2014/15/D/ST5/ 02574).

Open Access This article is distributed under the terms of the Creative Commons Attribution 4.0 International License (http://crea tivecommons.org/licenses/by/4.0/), which permits unrestricted use, distribution, and reproduction in any medium, provided you give appropriate credit to the original author(s) and the source, provide a link to the Creative Commons license, and indicate if changes were made.

\section{References}

1. Tallon C, Franks GV. Recent trends in shape forming from colloidal processing: a review. J Ceram Soc Jpn. 2011;119:147-60.

2. Yamada H, Suzuki TS, Uchikoshi T, Hozumi M, Saito T, Sakka Y. Analysis of abnormal grain growth of oriented $\mathrm{LiCoO}_{2}$ prepared by slip casting in a strong magnetic field. J Eur Ceram Soc. 2013;33:3059-64.

3. Bednarek P, Szafran M, Sakka Y, Mizerski T. Gelcasting of alumina with a new monomer synthesized from glucose. J Eur Ceram Soc. 2010;30:1795-801.

4. Szudarska A, Mizerski T, Sakka Y, Suzuki TS, Szafran M. Fabrication of textured alumina by magnetic alignment via gelcasting based on low-toxic system. J Eur Ceram Soc. 2014;34:384-8.

5. Blugan G, Morawa K, Koebel S, Graule T, Kuebler J. Development of a tape casting process for making thin layers of Si3N4 and Si3N4 + TiN. J Eur Ceram Soc. 2007;27:4789-95.

6. Takahashi M, Menchavez RL, Fuji M, Takegami H. Opportunities of porous ceramics fabricated by gelcasting in mitigating environmental issues. J Eur Ceram Soc. 2009;29:823-8.

7. Tomasik P, Schilling CH, Jankowiak R, Kim JC. The role of organic dispersants in aqueous alumina suspension. J Eur Ceram Soc. 2003;23:913-9.

8. Ament KA, Kessler MR, Akinc M. Shear thinning behavior of aqueous alumina nanoparticle suspensions with saccharides. Ceram Int. 2014;40:3533-42.

9. Elias J, Gizowska M, Brodard P, Widmer R, deHazan Y, Graule T, Michler J, Philippe L. Electrodeposition of gold thin films with controlled morphologies and their applications in electrocatalysis and SERS. Nanotechnology. 2012;23:255705.

10. Szafran M, Wisniewski P, Rokicki G. Effect of glass transition temperature of polymeric binders on properties ceramic materials. J Thermal Anal Calorim. 2004;77:319-27.

11. Michalek M, Blugan G, Graule T, Kuebler J. Comparison of aqueous and non-aqueous tape casting of fully stabilized $\mathrm{ZrO}_{2}$ suspensions. Powder Technol. 2015;274:276-83.

12. Potoczek M, Zima A, Paszkiewicz Z, Slosarczyk A. Manufacturing of highly porous calcium phosphate bioceramics via gelcasting using agarose. Ceram Int. 2009;35:2249-54.

13. Wiecinska P, Mizerski T, Szafran M. Monoacryloyl esters of carbohydrates: synthesis, polymerization and application in ceramic technology. Carbohydr Polym. 2014;111:610-8. 
14. Li F, Chen H, Wu R, Sun B. Effect of polyethylene glycol on the surface exfoliation of $\mathrm{SiC}$ green bodies prepared by gelcasting. Mater Sci Eng, A. 2004;368:255-9.

15. Sepulveda P, Binner JGP. Persulfate-amine initiation systems for gelcasting of ceramic foams. Chem Mater. 2001;13(11):4065-70.

16. Salehi M, Clemens F, Graule T, Grobety B. Kinetic analysis of the polymer burnout in ceramic thermoplastic processing of the YSZ thin electrolyte structures using model free method. Appl Energy. 2012;95:147-55.

17. Leszczynska A, Pielichowski K. Application of thermal analysis methods for characterization of polymer/montmorillonite nanocomposites. J Thermal Anal Calorim. 2008;93:677-87.

18. Sczygiel I, Winiarska K. Synthesis and characterization of manganese-zinc ferrite obtained by thermal decomposition from organic precursors. J Therm Anal Calorim. 2014;115:471-7.

19. Golofit T, Zysk K. Thermal decomposition properties and compatibility of CL-20 with binders HTPB, PBAN, GAP and polyNIMMO. J Therm Anal Calorim. 2015;119:1931-9.

20. Thom AJ, Summers E, Akinc M. Oxidation behavior of extruded Mo5Si3Bx-MoSi2-MoB intermetallics from $600^{\circ}$ to $1600^{\circ} \mathrm{C}$. Intermetallics. 2002;10:555-70.

21. Etienne S, Becker C, Ruch D, Germain A, Calberg C. Synergetic effect of poly(vinyl butyral) and calcium carbonate on thermal stability of poly(vinyl chloride) nanocomposites investigated by TG-FTIR-MS. J Thermal Anal Calorim. 2010;100:667-77.
22. Bednarek P, Szafran M. Thermal decomposition of monosaccharides derivatives applied in ceramic gelcasting process investigated by the coupled DTA/TG/MS analysis. J Therm Anal Calorim. 2012;109:773-82.

23. Wyrzykowski D, Hebanowska E, Nowak-Wiczk G, Makowski M, Chmurzynski L. Thermal behaviour of citric acid and isomeric aconitic acids. J Therm Anal Calorim. 2011;104:731-5.

24. Reda SY. Evaluation of antioxidants stability by thermal analysis and its protective effect in heated edible vegetable oil. Food Sci Technol. 2011;31(2):475-80.

25. Zuev VV, Bertini F, Audisio G. Investigation on the thermal degradation of acrylic polymers with fluorinated side-chains. Polym Degrad Stab. 2006;91:512-6.

26. Kokabi M, Babaluo AA, Barati A. Gelation process in low-toxic gelcasting systems. J Eur Ceram Soc. 2006;26:3083-90.

27. Ganesh I, Olhero SM, Torres PMC, Alves FJ, Ferreira JMF. Hydrolysis-induced aqueous gelcasting for near-net shape forming of ZTA ceramic composites. J Eur Ceram Soc. 2009;29:1393-401.

28. Wiecinska P, Graule T, Szafran M. L-Ascorbic acid as a new activator in fabrication of ceramics by techniques using in situ polymerization. J Eur Ceram Soc. 2014;34:1581-9.

29. Vorsina LA, Mikhailov YI. Kinetics of thermal decomposition of ammonium persulfate. Russ Chem Bull. 1996;45(3):539-41. 